\title{
The Public's views of mental health in pregnant and postpartum women: a population-based study
}

\author{
Dawn E Kingston ${ }^{1 *}$, Sheila Mcdonald ${ }^{2}$, Marie-Paule Austin ${ }^{3}$, Kathy Hegadoren ${ }^{1}$, Gerri Lasiuk ${ }^{1}$ and Suzanne Tough ${ }^{2}$
}

\begin{abstract}
Background: We used population-based data to determine the public's views of prenatal and postnatal mental health and to identify predictors of those views.

Methods: A computer-assisted telephone survey was conducted by the Population Health Laboratory (University of Alberta) with a random sample of participants from the province of Alberta, Canada. Respondents were eligible to participate if they were: 1) $\geq 18$ years; and 2) contacted by direct dialing. Questions were drawn from the Perinatal Depression Monitor, an Australian population-based survey on perinatal mental health; additional questions were developed and tested to reflect the Canadian context. Descriptive and multivariable regression analyses were conducted.
\end{abstract}

Results: Among the 1207 respondents, $74.7 \%$ had post-secondary education, 16.3\% were in childbearing years, and over half (57.4\%) reported knowing a woman who had experienced postpartum depression. Significantly more respondents had high levels of knowledge of postnatal (87.4\%) than prenatal $(70.5 \%)$ mental health $(p<.01)$. Only $26.6 \%$ of respondents accurately identified that prenatal anxiety/depression could negatively impact child development. Personal knowledge of a woman with postpartum depression was a significant predictor of prenatal and postnatal mental health knowledge.

Conclusions: While the public's knowledge of postnatal mental health is high, knowledge regarding prenatal mental health and its influence on child development is limited. Strategies for improving perinatal mental health literacy should target these knowledge deficits.

Keywords: Pregnancy, Postpartum, Mental health, Public views, Depression, Anxiety

\section{Background}

At a prevalence of 13 to $25 \%$, stress, depression, and anxiety are the most common complications experienced by women during the prenatal and postnatal periods $[1,2]$. Poor mental health during the perinatal period is identified as a major public health concern and "the biggest unaddressed health challenge of our age" [3]. Without treatment, over one-third of women with prenatal mental health problems will experience unremitting symptoms that persist into their child's preschool years [4]. However, despite frequent contact with healthcare professionals during pregnancy and post-delivery, the vast majority of women do not seek help for symptoms of stress, depression, or anxiety, or voluntarily disclose their symptoms $[5,6]$.

\footnotetext{
* Correspondence: Dawn.Kingston@ualberta.ca

${ }^{1} 5$-258 Edmonton Clinic Health Academy, Faculty of Nursing, University of Alberta, 11405-87th Avenue, Edmonton, AB T6C 1C9, Canada

Full list of author information is available at the end of the article
}

Women cite significant deterrents to disclosure and helpseeking during the perinatal period [5-8]. While some barriers that women describe are clearly system-related (e.g., not obtaining a referral in a timely manner) [7], many reflect deeply held views regarding mental health problems in the prenatal and postnatal periods, including the expectation of being constantly happy to be pregnant or have a new infant, the association of mental health problems with maternal incompetency and being a failure as a mother, the fear that others would think less of them if they admitted to experiencing symptoms, the need to be a 'super-mother', the concern that their infant would be apprehended, and the belief that symptoms would improve spontaneously [8-10].

Views regarding mental health and healthcare are poignant determinants of patient behavior with regard to the access, uptake, and adherence to mental health treatment. 
Among pregnant and postpartum women, negative or inaccurate views of mental health are impediments to early detection and treatment, in that they are associated with delay in seeking mental healthcare [5] and reduced disclosure of mental health problems [6]. Understanding views towards mental health is also foundational to delivering effective intervention. Evidence rooted in the field of implementation science suggests that effective implementation of interventions must incorporate knowledge of the context that influences the impact of the intervention and its transference into clinical care - with patient views being a central component of the context $[11,12]$. Thus, effective and sustainable intervention utilizes patient views to optimize its impact and utilization [11].

While the public's views surrounding mental health have been well studied with respect to general anxiety and depression, very little research has explored its views related to perinatal mental health. Three key observations highlight the importance of the investigation of the public's views of perinatal mental health:

1) Only one study to date has explored the public's views of perinatal mental health [13]; however, it is unclear whether these Australian findings are generalizable to other contexts in that they reflect the public's awareness of perinatal mental health within a healthcare system that supports the National Perinatal Depression Initiative $[14,15]$ and espouses highly visible, definitive perinatal mental health awareness strategies (http://www. beyondblue.org.au/);

2) Only a few, small studies have explored the views of mental health and healthcare among pregnant and postpartum women and their care providers [6,7,16-18]. Findings of these studies suggest that the most prominent attitudes toward mental health differ from studies conducted in the general population, and warrant a separate investigation. For example, surveys of public attitudes of mental health in the general population have identified social distance (e.g., not wanting to employ or befriend individuals with mental health problems) and stereotyping (e.g., as dangerous, to be blamed, unpredictable) as prominent concerns $[19,20]$. In the perinatal literature, attitudes toward mental health are uniquely embedded in concerns related to pregnancy or transitioning to motherhood, such as the belief that women with perinatal depression or anxiety are incompetent or bad mothers, and the guilt that originates from not feeling happy or being able to cope $[6,7]$; and

3) The views of childbearing couples are highly sensitive to societal values and opinions, with family and friends representing dominant influences on their behaviors and decisions $[5,8]$.

As such, understanding the public's views regarding depression and anxiety in the prenatal and postnatal periods provides a valuable foundation for gaining insight into decision-making, help-seeking, and healthcare utilization patterns of childbearing families.

The purpose of this study was to use a large, populationbased sample to describe the public's views of perinatal mental health on topics related to knowledge of preconception, prenatal, and postnatal mental health and their influence on maternal and child outcomes, and to identify factors associated with perinatal mental health knowledge.

\section{Methods}

\section{Overview}

The Alberta Survey-B is an annual, population-based survey conducted by the Population Research Laboratory (PRL) at the University of Alberta (Alberta, Canada). Each year, different sponsors submit questions of interest. In 2012, the Alberta Centre for Child, Family and Community Research sponsored 15 items designed to gather information on views about perinatal mental health. Questions addressed topics related to knowledge of the effects of anxiety and depression occurring during pre-conception, pregnancy, and postpartum periods; help-seeking for prenatal and postpartum anxiety and depression; and screening and treatment for pregnant and postpartum women with anxiety or depression. Questions were drawn from the Australian Perinatal Depression Monitor, a 26-item survey designed to measure population-based awareness, attitudes, and knowledge regarding prenatal and postnatal mental health [13]; additional questions were developed and tested for this survey to address the Canadian context. The latter were evaluated for face and content validity by 15 researchers, clinicians, and policy-makers with expertise in perinatal mental health. Participants selected responses to items related to perinatal mental health on a 5-point Likert scale ranging from strongly disagree to strongly agree. All questions were pre-tested by the PRL on 20 households to check wording, response categories, question order, interviewer instructions, and length of interview [21].

Random-digit dialing of several provincial telephone banks generated a random sample of households from rural and urban areas and ensured that the sampling frame included households with and without telephone directory listings [21]. Respondents were eligible to participate if they were: 1) $\geq 18$ years; and 2) contacted by direct dialing within the province. Following identification as an affiliate of the Population Health Laboratory and introduction to the study, agreement to participate in the telephone-based survey constituted consent. The study protocol was approved by the Research Ethics Board at the University of Alberta.

Data were collected between June 5, 2012 and June 27, 2012 by trained PRL interviewers using standardized, computer-assisted telephone interviews. Interviews were conducted in English and each lasted a 
maximum of 30 minutes. A random sample of $10 \%$ of the respondents were followed-up by PRL supervisors to verify accuracy of data collection.

\section{Outcomes}

The main outcomes were knowledge of: 1) the influence of past history of anxiety and depression; 2) prenatal mental health and its adverse sequelae; and 3) postnatal mental health and its adverse consequences. For each outcome, the dichotomized definition of 'high' and 'low' knowledge was based on an examination of the distribution of the variable. Knowledge of the influence of past history was considered high if respondents answered strongly or somewhat agree to the question, "Women who have had anxiety or depression in the past (before they became pregnant) are more likely to experience anxiety or depression when they are pregnant", and low if they responded strongly or somewhat disagree, or neither agree nor disagree. High level of prenatal mental health knowledge was defined by a response of strongly or somewhat agree to "Women who have had anxiety or depression in the past (before they became pregnant) are more likely to experience anxiety or depression when they are pregnant" and/or "Women who have anxiety or depression during pregnancy are more likely to experience postpartum depression", while those with low prenatal knowledge answered strongly or somewhat disagree to either or both questions. High postnatal knowledge was defined by a response of strongly or somewhat agree to at least one of three questions, including, "Women who have postpartum depression find it more difficult to respond to their baby's cues" and/or "Women who have postpartum depression find it more difficult to respond to the needs of their partner and other children" and/or "Partners of women who have postpartum depression are also at risk for depression", whereas those with low postnatal knowledge responded strongly or somewhat disagree to one or more of these questions.

\section{Analysis}

Descriptive data $(\mathrm{N}, \%)$ were generated for each variable and outcome. The Chi-square test was used to determine differences between selected categorical variables. Unadjusted odds ratios (UORs) and 95\% confidence intervals (CIs) were calculated for the outcomes of knowledge of prenatal and postnatal mental health. Variables associated with the outcomes at a level of $\mathrm{p}<.10$ in unadjusted analyses were entered into the final multivariable models after assessing for the presence of multicollinearity. Two multivariable models were constructed with all variables entered simultaneously to generate adjusted odds ratios (AORs) and 95\% CIs with $\mathrm{p}<.05$ defining statistically significant factors. Excluded variables were entered one at a time to assess the robustness of the final models. The analysis was conducted using SPSS (Version 21.0.0).

\section{Results}

The sample

Of the total eligible participants $(n=10,563), 3029$ refused, 29 interviews were incomplete, 102 interviews involved language problems, and 6196 were unavailable or not contacted (estimated eligible). In total, 1207 completed interviews were conducted with 603 females and 604 males. Approximately two-thirds of the sample lived in urban regions with one-third in rural areas. Respondents were most commonly $45-64$ years of age (45.8\%), with $16.3 \%$ being in childbearing years (18-34 years) (Table 1). Two-thirds of households had no children living in the household (66.3\%). The majority of respondents were married or living common-law (68.6\%), had completed post-secondary education $(74.7 \%)$, were born in Canada (81.8\%) and were Caucasian (85.4\%) (Table 1). Over half of the respondents reported knowing a woman who had experienced postpartum anxiety or depression (57.4\%).

\section{Knowledge of influence of past history of anxiety and depression}

Just over half of respondents strongly agreed/agreed that women with histories of anxiety or depression were more likely to experience anxiety or depression in pregnancy (57.2\%) with $32.2 \%$ reporting not knowing (15.7\%) or neither agreeing nor disagreeing (16.5\%) (Table 2). A similar proportion strongly agreed/agreed that prior episodes of anxiety or depression in pregnancy increased women's risk for postpartum depression (PPD) (60.9\%). With respect to both of these questions, only one-quarter of respondents strongly agreed that a history of mental health problems increased women's risk for poor prenatal and postnatal mental health (Table 2).

\section{Knowledge of prenatal mental health}

Over half of respondents agreed that women with anxiety or depression during pregnancy were more likely to experience PPD (60.9\%) (Table 1). Only one-quarter of respondents (26.6\%) agreed that children whose mothers were depressed or anxious during pregnancy were more likely to experience slower development; however, more than $40 \%$ of respondents reported that they did not know or were unsure. In the final multivariable model, participants who were older and did not know a woman who had experienced PPD were less likely to have high levels of knowledge of prenatal mental health (Table 3). Individuals who were not born in Canada were more likely to be knowledgeable than Canadian-born participants, as were those with a high level of knowledge of postnatal mental health. 
Table 1 Description of respondents of the 2012 Alberta-B survey (Alberta, Canada) $(\mathrm{N}=1207)$

\begin{tabular}{|c|c|}
\hline Variable & n (\%) \\
\hline \multicolumn{2}{|l|}{$\overline{S e x^{*}}$} \\
\hline Male & $603(50.0)$ \\
\hline Female & $604(50.0)$ \\
\hline \multicolumn{2}{|l|}{ Employment } \\
\hline Unemployed & $467(38.7)$ \\
\hline Employed & $739(61.3)$ \\
\hline \multicolumn{2}{|l|}{ Children (age < 18) in household } \\
\hline No & $798(66.3)$ \\
\hline Yes & $406(33.7)$ \\
\hline \multicolumn{2}{|l|}{ Age (years) } \\
\hline $18-24$ & $53(4.5)$ \\
\hline $25-34$ & $139(11.8)$ \\
\hline $35-44$ & $211(17.9)$ \\
\hline $45-54$ & $269(22.9)$ \\
\hline $55-64$ & $269(22.9)$ \\
\hline $65+$ & $235(20.0)$ \\
\hline \multicolumn{2}{|l|}{ Marital status } \\
\hline Single/widowed/divorced & $377(31.4)$ \\
\hline Married/common-law & $824(68.6)$ \\
\hline \multicolumn{2}{|c|}{ Education (highest level completed) } \\
\hline Less than high school & $96(7.9)$ \\
\hline High school completed & $209(17.4)$ \\
\hline Post-secondary & $898(74.7)$ \\
\hline \multicolumn{2}{|l|}{ Born in Canada } \\
\hline No & $220(18.2)$ \\
\hline Yes & $987(81.8)$ \\
\hline \multicolumn{2}{|l|}{ Born in Alberta } \\
\hline No & $403(40.9)$ \\
\hline Yes & $584(59.1)$ \\
\hline \multicolumn{2}{|l|}{ Ethnicity } \\
\hline Non-Caucasian & $186(14.6)$ \\
\hline Caucasian & $1023(85.4)$ \\
\hline \multicolumn{2}{|l|}{ Income } \\
\hline$<\$ 40,000$ & $129(13.7)$ \\
\hline$\geq \$ 40,000$ & $815(86.3)$ \\
\hline \multicolumn{2}{|l|}{ Residence* $^{*}$} \\
\hline Rural/other & 401 (33.3) \\
\hline Urban (planned) & $804(66.7)$ \\
\hline \multicolumn{2}{|l|}{ Personal experience } \\
\hline No & $503(42.6)$ \\
\hline Yes & $678(57.4)$ \\
\hline
\end{tabular}

\section{Knowledge of postnatal mental health}

Over two-thirds of respondents strongly agreed/agreed that women with PPD find it difficult to respond to their baby's cues $(68.6 \%)$ with a minimal proportion indicating that they did not know (9\%) (Table 2). The majority of respondents also agreed that women with PPD find it more difficult to respond to the needs of their partner or other children (79.8\%). However, fewer than half of respondents reported that partners of women with PPD were more likely to experience depression (45.1\%) with over $20 \%$ indicating that they strongly disagreed/disagreed (21.9\%) (Table 2). In the multivariable analysis, participants with no post-secondary education and who did not know a woman with PPD were less likely to have high levels of postnatal mental health knowledge (Table 4). Those with a high level of prenatal knowledge were over three times more likely to have high knowledge of postnatal mental health.

\section{Relationship between knowledge of prenatal and postnatal mental health}

Overall, more participants had high knowledge of postnatal mental health $(87.4 \%)$ than prenatal mental health $(70.5 \%)$ $(\mathrm{p}<.001)$. The Spearman's correlation between prenatal and postnatal knowledge was small at .248 $(\mathrm{p}=.01)$.

\section{Discussion}

This study provides the first Canadian data related to public views of perinatal mental health and adds to the limited body of evidence on this topic. Only one other study in Australia has described the public's views of perinatal mental health at a population-level [13]. Overall, we found that levels of knowledge of postnatal mental health were high, while knowledge regarding prenatal mental health was significantly lower. Understanding the contributions of past mental health problems and prenatal mental health on the risk of development of depression/anxiety during and after pregnancy was also quite low. The least understood topic was the influence of prenatal mental health on child development, where only one in four participants responded accurately, and over $40 \%$ reported that they were unsure or did not know. Finally, our multivariable analyses revealed that the main determinants of both prenatal and postnatal mental health were personal experience with PPD and possessing high levels of knowledge of mental health across the perinatal period. Whereas most demographic variables were not significant, we found that older participants and those with no postsecondary education had significantly lower levels of prenatal and postnatal mental health knowledge, respectively.

Our finding that respondents were more knowledgeable about postnatal than prenatal mental health is similar to the Australian study in which $24.8 \%$ of individuals cited PPD as a major health problem, but only $7.0 \%$ of participants recognized the health implications of prenatal 
Table 2 Prevalence of outcomes ( $n, \%)$ among respondents to the 2012 Alberta-B survey (Alberta, Canada) $(N=1207)$

Variable
Women who have had anxiety or depression
in the past (before they became pregnant)
are more likely to experience anxiety or
depression when they are pregnant
Strongly disagree
Disagree
Neither agree nor disagree
Agree
Strongly agree
No response/don't know

Women who have anxiety or depression during pregnancy are more likely to experience postpartum depression

Strongly disagree
Disagree
Neither agree nor disagree
Agree

Strongly agree

No response/don't know

Women who have postpartum depression find it more difficult to respond to their baby's cues

Strongly disagree
Disagree
Neither agree nor disagree
Agree
Strongly agree
No response/don't know

Women who have postpartum depression find it more difficult to respond to the needs of their partner and other children

Strongly disagree
Disagree
Neither agree nor disagree
Agree
Strongly agree

No response/don't know

Partners of women who have postpartum depression are also at risk for depression

$\begin{array}{lc}\text { Strongly disagree } & 105(8.7) \\ \text { Disagree } & 160(13.2) \\ \text { Neither agree nor disagree } & 232(19.3) \\ \text { Agree } & 390(32.3) \\ \text { Strongly agree } & 155(12.8) \\ \text { No response/don't know } & 164(13.6) \\ \text { nowledge of prenatal mental health } & \end{array}$

Table 2 Prevalence of outcomes ( $n, \%)$ among respondents to the 2012 Alberta-B survey (Alberta, Canada) $(N=1207)$ (Continued)

\begin{tabular}{lc}
\hline High & $831(70.5)$ \\
Low & $347(29.5)$ \\
Knowledge of postnatal mental health & $1028(87.4)$ \\
High & $148(12.6)$ \\
Low &
\end{tabular}

anxiety or depression [13]. Indeed, in this study $52 \%$ of respondents identified prenatal anxiety as 'normal' [13]. The limited understanding of determinants of prenatal and postnatal anxiety/depression is also consistent with this study's report of common, erroneous beliefs regarding the causes of postnatal depression expressed by both the general public and healthcare providers [13]. The lack of knowledge about the influence of pre-conception and prenatal anxiety/depression on the risk of poor perinatal mental health [22-24] may reflect errant public belief that the primary causes of perinatal mental health problems are biological in nature -a key observation noted in the Australian study [13]. The failure to recognize the role that other factors play may underlie women's dread regarding a diagnosis of PPD and their reticence in help-seeking in that a deterministic, biological view implies that women are bound to develop PPD and prevention is not possible.

The disparity that we observed in the public's prenatal and postnatal mental health knowledge is notable in that qualitative studies have cited major deterrents to mental health help-seeking in pregnancy as lack of knowledge regarding symptoms, where to find help, and treatment options [5,6]. Furthermore, other studies have related low knowledge of mental health among perinatal healthcare providers to sub-optimal mental health screening behavior [18], which has been reported as less than $20 \%$ [25]. Thus, a major concern originating from our findings is that limited awareness of prenatal mental health problems may contribute to the serious under-detection and under-treatment $[25,26]$ of prenatal mental health problems. Improving perinatal mental health knowledge (e.g., symptoms, where to seek help, treatment options) among women, their families, and healthcare providers may have a substantial impact on detection and treatment.

Emerging evidence indicates that early intervention to improve pregnant women's mental health has enduring benefits for reducing the risk of postpartum mental health problems and poor infant health and development [27-29]. Thus, although the historical focus has been on diagnosing and treating PPD, the findings of this study highlight the need for a shift toward improving the public's understanding of the prevalence and sequelae of prenatal anxiety and depression. The strikingly low level of understanding of the 
Table 3 Unadjusted (UOR) and Adjusted Odds Ratios (AOR) of factors associated with knowledge of prenatal mental health in the 2012 Alberta-B survey (Alberta, Canada) $(\mathrm{N}=1207)$

\begin{tabular}{|c|c|c|c|c|c|c|}
\hline Variable & $\begin{array}{c}\text { High level of prenatal mental } \\
\text { health knowledge } \\
\mathrm{N}(\%)\end{array}$ & $\begin{array}{c}\text { Low level of prenatal mental } \\
\text { health knowledge } \\
\mathrm{N}(\%)\end{array}$ & UOR & $95 \% \mathrm{Cl}$ & AOR & $95 \% \mathrm{Cl}$ \\
\hline \multicolumn{7}{|l|}{ Sex } \\
\hline Male & $390(67.2)$ & $190(32.8)$ & $.73^{*}$ & $.57-.94$ & .81 & $.62-1.06$ \\
\hline Female & $441(73.7)$ & $157(26.3)$ & 1.00 & & & \\
\hline \multicolumn{7}{|l|}{ Employment } \\
\hline Unemployed & $314(69.3)$ & $139(30.7)$ & .91 & $.70-1.17$ & & \\
\hline Employed & $517(71.4)$ & $207(28.6)$ & 1.00 & & & \\
\hline \multicolumn{7}{|l|}{ Children (age < 18) in household } \\
\hline No & $543(70.2)$ & $231(29.8)$ & .96 & $.73-1.25$ & & \\
\hline Yes & $285(71.7)$ & $116(28.9)$ & 1.00 & & & \\
\hline \multicolumn{7}{|l|}{ Age (in childbearing years: 18-35) } \\
\hline No & $666(69.2)$ & $297(30.8)$ & $.54^{*}$ & $.36-.79$ & .52 & $.35-.78$ \\
\hline Yes & $151(80.7)$ & $36(29.3)$ & 1.00 & & & \\
\hline \multicolumn{7}{|l|}{ Marital status } \\
\hline Single/widowed/divorced & $267(73.6)$ & $96(26.4)$ & 1.23 & $.94-1.63$ & & \\
\hline Married/common-law & $561(69.3)$ & $249(30.7)$ & 1.00 & & & \\
\hline \multicolumn{7}{|l|}{ Education } \\
\hline No post-secondary education & $212(71.9)$ & $83(28.1)$ & 1.08 & $.81-1.45$ & & \\
\hline At least some post-secondary education & $617(70.3)$ & $261(29.7)$ & 1.00 & & & \\
\hline \multicolumn{7}{|l|}{ Born in Canada } \\
\hline No & $162(75.7)$ & $52(24.3)$ & $1.37^{*}$ & $.98-1.93$ & 1.80 & $1.23-2.64$ \\
\hline Yes & $669(69.4)$ & $295(30.6)$ & 1.00 & & & \\
\hline \multicolumn{7}{|l|}{ Born in Alberta } \\
\hline No & $274(68.8)$ & $124(31.2)$ & .96 & $.73-1.26$ & & \\
\hline Yes & $395(69.8)$ & $171(30.2)$ & 1.00 & & & \\
\hline \multicolumn{7}{|l|}{ Ethnicity } \\
\hline Non-Caucasian & $125(72.7)$ & $47(27.3)$ & 1.12 & $.78-1.61$ & & \\
\hline Caucasian & $702(70.3)$ & $296(29.7)$ & 1.00 & & & \\
\hline \multicolumn{7}{|l|}{ Income } \\
\hline$<\$ 40,000$ & $93(73.8)$ & $33(26.2)$ & 1.21 & $.79-1.85$ & & \\
\hline$\geq \$ 40,000$ & $561(70.0)$ & $241(30.0)$ & 1.00 & & & \\
\hline \multicolumn{7}{|l|}{ Residence } \\
\hline Rural/other & $283(72.6)$ & $107(27.4)$ & 1.16 & $.89-1.52$ & & \\
\hline Urban & $548(69.5)$ & $240(30.5)$ & 1.00 & & & \\
\hline \multicolumn{7}{|l|}{ Personal experience } \\
\hline No & $315(63.8)$ & $179(36.2)$ & $.56^{*}$ & $.44-.72$ & .65 & $.50-.86$ \\
\hline Yes & $514(75.8)$ & $164(24.2)$ & 1.00 & & & \\
\hline \multicolumn{7}{|l|}{ Postnatal knowledge } \\
\hline High & 770 & 254 & $4.35^{*}$ & $3.04-6.22$ & 3.88 & $2.65-5.67$ \\
\hline Low & 60 & 86 & 1.00 & & & \\
\hline
\end{tabular}

*Met criterion for inclusion in multivariable model $(p<.10)$.

Note. $\mathrm{UOR}=$ unadjusted odds ratio; $\mathrm{AOR}=$ adjusted odds ratio; $\mathrm{Cl}=$ confidence interval. 
Table 4 Unadjusted (UOR) and Adjusted Odds Ratios (AOR) of factors associated with knowledge of postnatal mental health in the 2012 Alberta-B survey (Alberta, Canada) $(N=1207)$

\begin{tabular}{|c|c|c|c|c|c|c|}
\hline Variable & $\begin{array}{l}\text { High level of postnatal mental } \\
\text { health knowledge } \\
N(\%)\end{array}$ & $\begin{array}{l}\text { Low level of postnatal mental } \\
\text { health knowledge } \\
\mathrm{N}(\%)\end{array}$ & UOR & $95 \% \mathrm{Cl}$ & AOR & $95 \% \mathrm{Cl}$ \\
\hline \multicolumn{7}{|l|}{ Sex } \\
\hline Male & $494(85.2)$ & $86(14.8)$ & $.67^{*}$ & $.47-.95$ & .86 & $.56-1.32$ \\
\hline Female & $534(89.6)$ & $62(10.4)$ & 1.00 & & & \\
\hline \multicolumn{7}{|l|}{ Employment } \\
\hline Unemployed & $386(85.6)$ & $65(14.4)$ & .77 & $.54-1.09$ & & \\
\hline Employed & $641(88.5)$ & $83(11.5)$ & 1.00 & & & \\
\hline \multicolumn{7}{|l|}{ Children (age < 18) in household } \\
\hline No & $671(86.7)$ & $103(13.3)$ & .83 & $.57-1.20$ & & \\
\hline Yes & $354(88.7)$ & $45(11.3)$ & 1.00 & & & \\
\hline \multicolumn{7}{|l|}{ Age (in childbearing years: 18-35) } \\
\hline No & $840(87.5)$ & $120(12.5)$ & .93 & $.58-1.52$ & & \\
\hline Yes & $165(88.2)$ & $22(11.8)$ & 1.00 & & & \\
\hline \multicolumn{7}{|l|}{ Marital status } \\
\hline Single/widowed/divorced & $312(86.2)$ & $50(13.8)$ & .85 & $.59-1.23$ & & \\
\hline Married/common-law & $712(88.0)$ & $97(12.0)$ & 1.00 & & & \\
\hline \multicolumn{7}{|l|}{ Education } \\
\hline No post-secondary education & $242(82.6)$ & $51(17.4)$ & $.58^{*}$ & $.40-.84$ & .46 & $.29-.73$ \\
\hline Post-secondary & $782(89.1)$ & $96(10.9)$ & 1.00 & & & \\
\hline \multicolumn{7}{|l|}{ Born in Canada } \\
\hline No & $175(82.9)$ & $36(17.1)$ & $.64^{*}$ & $.42-.96$ & .58 & $.33-1.02$ \\
\hline Yes & $853(88.4)$ & $112(11.6)$ & 1.00 & & & \\
\hline \multicolumn{7}{|l|}{ Born in Alberta } \\
\hline No & $351(88.2)$ & $47(11.8)$ & .97 & $.65-1.44$ & & \\
\hline Yes & $502(88.5)$ & $65(11.5)$ & 1.00 & & & \\
\hline \multicolumn{7}{|l|}{ Ethnicity } \\
\hline Non-Caucasian & $139(81.8)$ & $31(18.2)$ & $.58^{*}$ & $.37-.89$ & .62 & $.34-1.12$ \\
\hline Caucasian & $885(88.6)$ & $114(11.4)$ & 1.00 & & & \\
\hline \multicolumn{7}{|l|}{ Income } \\
\hline$<\$ 40,000$ & $102(82.3)$ & $22(17.7)$ & $.64^{*}$ & $.38-1.06$ & .79 & $.44-1.41$ \\
\hline$\geq \$ 40,000$ & 706 (87.9) & $97(12.1)$ & 1.00 & & & \\
\hline \multicolumn{7}{|l|}{ Residence } \\
\hline Rural/Other & $335(86.1)$ & $54(13.9)$ & .84 & $.59-1.21$ & & \\
\hline Urban & $693(88.1)$ & $94(11.9)$ & 1.00 & & & \\
\hline \multicolumn{7}{|l|}{ Personal experience } \\
\hline No & $406(82.5)$ & $86(17.5)$ & $.43^{*}$ & $.30-.62$ & .58 & $.38-.88$ \\
\hline Yes & $620(91.6)$ & $57(8.4)$ & 1.00 & & & \\
\hline \multicolumn{7}{|l|}{ Prenatal knowledge } \\
\hline High & 770 & 254 & $4.35^{*}$ & $3.04-6.22$ & 3.47 & $2.28-5.29$ \\
\hline Low & 60 & 86 & 1.00 & & & \\
\hline
\end{tabular}

*Met criterion for inclusion in multivariable model $(p<.10)$.

Note. $\mathrm{UOR}=$ unadjusted odds ratio; $\mathrm{AOR}=$ adjusted odds ratio; $\mathrm{Cl}=$ confidence interval. 
impact of prenatal mental health on child development that we found mirrors the findings of other population-based studies that highlight two key points: 1) the public dismisses the importance of the early life influences on longterm child well-being [30]; and 2) knowledge of factors that influence child development is poor [31].

The finding that older age was related to lower prenatal mental knowledge is similar to the Australian study [13] that reported that fewer older adults identified mental health problems as concerns in the postpartum period compared to younger adults. Other studies have demonstrated that low income and education are associated with low mental health literacy [32]; however, we observed that only low education was related to postnatal knowledge and neither was related to prenatal knowledge. Indeed, the most consistent predictor of prenatal and postnatal knowledge was personally knowing a woman who had experienced postpartum anxiety or depression. The positive role of personal experience on the attitudes of perinatal healthcare providers toward mental health has been reported previously [33]. Our results confirm that this is an important determinant of perinatal mental health literacy in the general public.

\section{Limitations}

Because the questions were a component of a larger survey of diverse topics, we were limited in the scope of topics we could address and could not gather data on other important areas such as views regarding symptoms of perinatal depression/anxiety [13,19]. In addition, participants were not asked to identify their occupation, and thus we were unable to identify the views of healthcare professionals.

\section{Conclusions}

This study highlights the lack of public awareness about prenatal mental health problems and the impact of poor perinatal mental health on future maternal mental and child development. Recommendations based on the findings include strengthening public awareness of the determinants of poor perinatal mental health and the potential influence of poor perinatal mental health on child development. However, messages regarding the association between prenatal and postnatal mental health and child outcomes need to be constructed with great care and sensitivity to avoid inflicting unnecessary guilt on childbearing women. Future research should examine the impact of perinatal mental health literacy on screening, referral, and treatment patterns.

\footnotetext{
Abbreviations

AOR: Adjusted odds ratio; Cl: Confidence interval; PRL: Population Research Laboratory; UOR: Unadjusted odds ratio.
}

\section{Competing interests}

The authors declare that they have no competing interests.

\section{Authors' contributions}

DK conceptualized the study, participated in the development of the survey, was a consultant to the Population Research Laboratory on the testing of the survey, conducted data analysis, interpreted findings, drafted the manuscript and made final revisions. SM assisted with conceptualization of the study, data analysis, review of the findings, interpretation of the data, critical review and approval of the manuscript. M-PA reviewed and interpreted the results, critically reviewed the manuscript and approved the final version to be published. KH contributed to the development of the survey, critically reviewed the manuscript and approved the final version to be published. GL contributed to survey development, critically reviewed the manuscript and approved the final version for publication. ST aided in conceptualizing the study, participated in the development of the survey, interpreted the findings, critically reviewed the manuscript and approved the final version to be published. All authors meet criteria for authorship. All authors read and approved the final manuscript.

\section{Authors' information}

DK (PhD) is an Assistant Professor in the Faculty of Nursing and an Adjunct Assistant Professor in the Department of Obstetrics and Gynecology at the University of Alberta. She holds an Early Career Transition Award through the Alberta Centre for Child, Family, and Community Research. MPA (MD, FRANZCP, MB) is a perinatal psychiatrist and Professor in the Faculty of Medicine at University of New South Wales. She is also the Chair of the Perinatal and Women's Mental Health Unit at the University of New South Wales, the Director of the St. John of God Mother-Baby Unit in Sydney, Australia, and the lead developer of the Australian Clinical Guidelines for Perinatal Mental Health (2011) and the International Marce Society Position Statement on Psychosocial Assessment and Depression Screening in the Perinatal Period (2013). KMH (PhD) is a Professor in the Faculty of Nursing and an Adjunct Professor in the Department of Psychiatry at the University of Alberta. She holds a Canada Research Chair in Stress Disorders in Women. $\mathrm{GL}(\mathrm{PhD})$ is an Associate Professor in the Faculty of Nursing at the University of Alberta and is a Certified Psychiatric Nurse. SM (PhD) is an epidemiologist with expertise in statistics, life course analysis, and mental health tool development. She is the senior scientist for the All Our Babies birth cohort study. ST is a Professor in the Department of Paediatrics and Community Health Sciences (Medicine) at the University of Calgary and an Adjunct Professor in the School of Public Health and Department of Obstetrics and Gynecology at the University of Alberta. She is a Health Scholar (Alberta Innovates-Health Solutions) and the Scientific Director of the Alberta Centre for Child, Family and Community Research.

\section{Acknowledgements}

We thank the Alberta Centre for Child, Family, and Community Research for financially supporting this research.

\section{Author details}

${ }^{1}$ 5-258 Edmonton Clinic Health Academy, Faculty of Nursing, University of Alberta, 11405-87th Avenue, Edmonton, AB T6C 1C9, Canada. ${ }^{2}$ Department of Pediatrics and Community Health Sciences, University of Calgary, Faculty of Medicine, 3280 Hospital Dr. NW, Calgary, AB T2N 4Z6, Canada. ${ }^{3}$ University of New South Wales (AU), High St., Kensington NSW 2052, Australia.

Received: 11 September 2013 Accepted: 18 February 2014 Published: 24 February 2014

\section{References}

1. Kingston D, Heaman M, Fell D, Dzakpasu S, Chalmers B: Factors associated with perceived stress and stressful life events in pregnant women: findings from the Canadian maternity experiences survey. Matern Child Health J 2012, 16(1):158-168.

2. Priest $S R$, Austin MP, Barnett BB, Buist $A$ : A psychosocial risk assessment model (PRAM) for use with pregnant and postpartum women in primary care settings. Arch women's ment health 2008, 11(5-6):307-317.

3. Lancet: Editorial: bring postnatal depression out of the shadows. Lancet 2012, 380(9854):1.

4. Horwitz SM, Briggs-Gowan MJ, Storfer-Isser A, Carter AS: Persistence of maternal depressive symptoms throughout the early years of childhood. J women's health 2009, 18(5):637-645.

5. Dennis CL, Chung-Lee L: Postpartum depression help-seeking barriers and maternal treatment preferences: a qualitative systematic review. Birth 2006, 33(4):323-331. 
6. Chew-Graham CA, Sharp D, Chamberlain E, Folkes L, Turner KM: Disclosure of symptoms of postnatal depression, the perspectives of health professionals and women: a qualitative study. BMC Fam Pract 2009, 10:7

7. Byatt N, Moore Simas TA, Lundquist RS, Johnson JV, Ziedonis DM: Strategies for improving perinatal depression treatment in North American outpatient obstetric settings. J Psychosom Obstet Gynaecol 2012 33(4):143-161.

8. Sword W, Busser D, Ganann R, McMillan T, Swinton M: Women's care-seeking experiences after referral for postpartum depression. Qual Health Res 2008, 18(9):1161-1173.

9. Flynn HA, Henshaw E, O'Mahen H, Forman J: Patient perspectives on improving the depression referral processes in obstetrics settings: a qualitative study. Gen Hosp Psychiatry 2010, 32(1):9-16.

10. Byatt N, Biebel K, Friedman L, Debordes-Jackson G, Ziedonis D, Pbert L: Patient's views on depression care in obstetric settings: how do they compare to the views of perinatal health care professionals? Gen Hosp Psychiatry 2013, 35(6):598-604.

11. Craig P, Dieppe P, Macintyre S, Michie S, Nazareth I, Petticrew M, Medical Research Council G: Developing and evaluating complex interventions: the new medical research council guidance. BMJ 2008, 337:a1655.

12. Gunn JM, Palmer VJ, Dowrick CF, Herrman HE, Griffiths FE, Kokanovic R, Blashki GA, Hegarty KL, Johnson CL, Potiriadis M, May CR: Embedding effective depression care: using theory for primary care organisational and systems change. Implementation sci: IS 2010, 5:62.

13. Highet NJ, Gemmill AW, Milgrom J: Depression in the perinatal period: awareness, attitudes and knowledge in the Australian population. Aust $N$ Z J Psychiatry 2011, 45(3):223-231.

14. Austin MP, Reilly N, Milgrom J, Barnett B: A national approach to perinatal mental health in Australia: exercising caution in the roll-out of a public health initiative. Med J Aust 2010, 192(2):111.

15. Austin MP, Middleton PF, Highet NJ: Australian mental health reform for perinatal care. Med J Aust 2011, 195(3):112-113.

16. Chew-Graham C, Chamberlain E, Turner K, Folkes L, Caulfield L, Sharp D: GPs' and health visitors' views on the diagnosis and management of postnatal depression: a qualitative study. Br J Gen Pract 2008, 58(548):169-176.

17. Edge D: Falling through the net - black and minority ethnic women and perinatal mental healthcare: health professionals' views. Gen Hosp Psychiatry 2010, 32(1):17-25.

18. Kim JJ, La Porte LM, Adams MG, Gordon TE, Kuendig JM, Silver RK: Obstetric care provider engagement in a perinatal depression screening program. Arch women's ment health 2009, 12(3):167-172.

19. Angermeyer $M C$, Holzinger $A$, Matschinger $\mathrm{H}$ : Mental health literacy and attitude towards people with mental illness: a trend analysis based on population surveys in the eastern part of Germany. Eur Psychiatry 2009, 24(4):225-232

20. Schomerus G, Schwahn C, Holzinger A, Corrigan PW, Grabe HJ, Carta MG, Angermeyer MC: Evolution of public attitudes about mental illness: a systematic review and meta-analysis. Acta Psychiatr Scand 2012, 125(6):440-452.

21. Laboratory PH: 2012 Alberta Survey B Methodology Report. Edmonton, Alberta: University of Alberta; 2012.

22. Bunevicius R, Kusminskas L, Bunevicius A, Nadisauskiene RJ, Jureniene K, Pop VJ: Psychosocial risk factors for depression during pregnancy. Acta Obstet Gynecol Scand 2009, 88(5):599-605.

23. Milgrom J, Gemmill AW, Bilszta JL, Hayes B, Barnett B, Brooks J, Ericksen J, Ellwood D, Buist A: Antenatal risk factors for postnatal depression: a large prospective study. J Affect Disord 2008, 108(1-2):147-157.

24. Giardinelli L, Innocenti A, Benni L, Stefanini MC, Lino G, Lunardi C, Svelto V, Afshar S, Bovani R, Castellini G, Faravelli C: Depression and anxiety in perinatal period: prevalence and risk factors in an Italian sample. Arch of women's ment health 2012, 15(1):21-30.

25. Mitchell AJ, Coyne J: Screening for postnatal depression: barriers to success. BJOG 2009, 116(1):11-14.

26. Carroll JC, Reid AJ, Biringer A, Midmer D, Glazier RH, Wilson L, Permaul JA, Pugh P, Chalmers B, Seddon F, Stewart DE: Effectiveness of the Antenatal Psychosocial Health Assessment (ALPHA) form in detecting psychosocial concerns: a randomized controlled trial. CMAJ 2005, 173(3):253-259.

27. Milgrom J, Schembri C, Ericksen J, Ross J, Gemmill AW: Towards parenthood: an antenatal intervention to reduce depression, anxiety and parenting difficulties. J Affect Disord 2011, 130(3):385-394.
28. Kozinszky Z, Dudas RB, Devosa I, Csatordai S, Toth E, Szabo D, Sikovanyecz J, Barabas K, Pal A: Can a brief antepartum preventive group intervention help reduce postpartum depressive symptomatology? Psychother Psychosom 2012, 81(2):98-107.

29. El-Mohandes AA, Kiely M, Gantz MG, El-Khorazaty MN: Very preterm birth is reduced in women receiving an integrated behavioral intervention: a randomized controlled trial. Matern Child Health J 2011, 15(1):19-28.

30. Davey L: Talking child mental health and the core story of child development in Alberta. Washington, D.C: FrameWorks Institute; 2010.

31. Rikhy S, Tough S, Trute B, Benzies K, Kehler H, Johnston DW: Gauging knowledge of developmental milestones among Albertan adults: a cross-sectional survey. BMC public health 2010, 10(1):183.

32. Reavley NJ, Jorm AF: Recognition of mental disorders and beliefs about treatment and outcome: findings from an Australian national survey of mental health literacy and stigma. Aust N Z J Psychiatry 2011, 45(11):947-956.

33. Leddy M, Haaga D, Gray J, Schulkin J: Postpartum mental health screening and diagnosis by obstetrician-gynecologists. J Psychosom Obstet Gynaecol 2011, 32(1):27-34.

doi:10.1186/1471-2393-14-84

Cite this article as: Kingston et al.: The Public's views of mental health in pregnant and postpartum women: a population-based study. BMC Pregnancy and Childbirth 2014 14:84.

\section{Submit your next manuscript to BioMed Central and take full advantage of:}

- Convenient online submission

- Thorough peer review

- No space constraints or color figure charges

- Immediate publication on acceptance

- Inclusion in PubMed, CAS, Scopus and Google Scholar

- Research which is freely available for redistribution 